\title{
Transcriptomic and functional analysis of the Anopheles gambiae salivary gland in relation to blood feeding
}

\author{
Suchismita Das ${ }^{1}$, Andrea Radtke ${ }^{1}$, Young-Jun Choi ${ }^{2}$, Antonio M Mendes ${ }^{1,3}$, Jesus G Valenzuela ${ }^{4}$, \\ George Dimopoulos ${ }^{1 *}$
}

\begin{abstract}
Background: The Anopheles gambiae salivary glands play a major role in malaria transmission and express a variety of bioactive components that facilitate blood-feeding by preventing platelet aggregation, blood clotting, vasodilatation, and inflammatory and other reactions at the probing site on the vertebrate host.

Results: We have performed a global transcriptome analysis of the A. gambiae salivary gland response to bloodfeeding, to identify candidate genes that are involved in hematophagy. A total of 4,978 genes were found to be transcribed in this tissue. A comparison of salivary gland transcriptomes prior to and after blood-feeding identified 52 and 41 transcripts that were significantly up-regulated and down-regulated, respectively. Ten genes were further selected to assess their role in the blood-feeding process using RNAi-mediated gene silencing methodology. Depletion of the salivary gland genes encoding D7L2, anophelin, peroxidase, the SG2 precursor, and a 5'nucleotidase gene significantly increased probing time of $A$. gambiae mosquitoes and thereby their capacity to blood-feed.

Conclusions: The salivary gland transcriptome comprises approximately 38\% of the total mosquito transcriptome and a small proportion of it is dynamically changing already at two hours in response to blood feeding. A better understanding of the salivary gland transcriptome and its function can contribute to the development of pathogen transmission control strategies and the identification of medically relevant bioactive compounds.
\end{abstract}

\section{Background}

Adult mosquitoes feed on sugar to obtain energy for flight and other activities, while anautogenous females need a blood meal to develop eggs. Salivary glands and the saliva of insect disease vectors have attracted considerable attention because of their role in pathogen transmission and their production of pharmacologically active factors [1-4].

It is during the blood-feeding process that the Plasmodium parasite is taken up from an infected A. gambiae host. Once inside the mosquito, Plasmodium undergoes several developmental transitions and eventually becomes a sporozoite, which invades the salivary glands. This invasion represents a critical step in the

\footnotetext{
* Correspondence: gdimopou@jhsph.edu

'W. Harry Feinstone Department of Molecular Microbiology and Immunology, Bloomberg School of Public Health, Johns Hopkins University, 615 N Wolfe Street, Baltimore, MD 21205-2179, USA

Full list of author information is available at the end of the article
}

transmission of the parasite to the vertebrate host. Completion of the infection depends on the injection of sporozoites, through the saliva, into the host's skin and leaving the inoculation site rapidly to enter and invade the liver for further development $[5,6]$.

Unlike male salivary glands, female mosquito salivary glands possess anti-hemostatic, vasodilatory and immune-modulatory factors to facilitate the acquisition of blood, while salivary glands of both sexes have activity related to the digestion of the sugar meal as well as antimicrobials to prevent microbial growth $[7,8]$. Mosquitoes have been shown to require longer probing times during blood-feeding when an apyrase gene (an enzyme that counteracts hemostasis) has been silenced, or if they are deprived of salivation by removal of the salivary duct through which the saliva is transported to the probing site $[9,10]$. Silencing of another A. gambiae salivary gland gene, SG6 (a small protein with unknown function), results in increased probing time and reduced 
blood-feeding ability [11]. Previous studies have shown that several Anopheles salivary gland proteins are reduced after blood-feeding, suggesting that these major polypeptides may have been introduced into the vertebrate hosts during the blood meal $[12,13]$. There is evidence that the pharmacological activity of arthropod saliva affects pathogen transmission and the local inflammatory response of the host. For example, the salivary gland lysate from the sand fly Lutzomyia longipalpis facilitates the infection of mice by the protozoan parasite Leishmania major [14,15]. It has also been shown that the L. longipalpis salivary gland lysate inhibits neutrophil migration and the Th1 immune inflammatory response. These findings suggest that the compounds responsible for such activities could be used for the development of novel anti-inflammatory drugs [4].

While earlier sialo-transcriptomic studies have identified a variety of salivary gland genes, [1,16-21], we present the first global microarray transcriptome analysis of the A. gambiae salivary gland under conditions related to feeding. Earlier studies have identified some 3,000 adult female A. gambiae salivary gland-transcribed sequence tags and 4,719 genes were found to be transcribed in the larval gland [22], of which 747 were specific for this tissue. Here we report 4,978 adult female A. gambiae salivary gland transcripts, as defined by oligonucleotide microarray gene transcription analysis. We show that 52 and 41 salivary gland-expressed transcripts were up-regulated and down-regulated, respectively, at 2 hours after blood-feeding when compared to salivary glands of unfed mosquitoes. We have also used an RNAi-mediated gene silencing approach to assess the potential involvement of 10 selected salivary gland genes in regulating mosquito blood-feeding capacity. Silencing of several salivary gland transcripts; D7L2, anophelin, peroxidase, 5'nucleotidase and SG2 precursor, produced a significantly lowered blood-feeding phenotype and increased probing time, confirming that these genes may be playing an important role in bloodfeeding. The updated list of the A. gambiae salivary gland transcriptome, together with the results of our comprehensive functional analyses, can facilitate the discovery of novel pharmacologically active compounds and provide tools for the development of malaria control strategies.

\section{Results and Discussion}

\section{The $A$. gambiae salivary gland transcriptome}

In order to characterize the A. gambiae female salivary gland transcriptome, we employed a microarray-based genome transcription approach to compare the transcript abundance in the salivary glands at 2 hours after blood feeding to salivary glands of unfed female mosquitoes. The relative transcript abundance of salivary gland expressed genes was analyzed by sorting the blood-fed versus unfed salivary gland transcripts into three different categories based on their corresponding spot fluorescence intensities (Figure 1A,B,C; see Additional file 1). Of the total predicted transcriptome (13,133 genes of $A$. gambiae, according to version 48, ENSEMBL); 4,978 genes (38\%) genes were found to be transcribed in the salivary gland of 4-day-old A. gambiae female mosquitoes. Of these, 267 transcripts $(2.1 \%)$ were considered as highly abundant (with fluorescence values ranging from 5,000 to the maximum threshold of 65,000; Figure 1A and Sheet 1 of Additional file 1); 482 transcripts $(3.6 \%)$ were considered as moderately present (fluorescence values ranging from 1,000 to 4,999; Figure $1 \mathrm{~B}$ and Sheet 2 of Additional file 1), and 4,229 transcripts $(32.2 \%)$ were considered as being present at low levels based on spot intensity (fluorescence values ranging from 100 to 999; Figure $1 \mathrm{C}$ and Sheet 3 of Additional file 1).

We analyzed the predicted functional class composition of each category (discussed below) to gain insight into the major processes that take place in the female mosquito's salivary glands upon blood-feeding.

\section{Cytoskeletal and structural genes}

Several cytoskeletal and structural gene transcripts (9 highly, 25 moderately, and 133 weakly transcribed) were identified in the salivary glands (Figure 1A, B, C and see Additional file 1). One of the most abundant transcripts encoded a mucin, a secretory protein that has been shown to be a major protein in the salivary gland lysate of several mosquito species $[1,16,19]$. This protein may function as a lubricant of the mosquito mouthparts and has been proposed to bind to the chitinous linings of the salivary ducts and mouthparts $[1,23]$. Three mucin encoding transcripts have been identified in the $A$. gambiae larval salivary gland [22], suggesting the importance of mucins at multiple developmental stages. We have further investigated the function of one of the mucin gene (AGAP001192-RA) by assaying changes in the feeding and probing behavior of mosquitoes after its depletion through RNAi (discussed below). In addition, Saglin (AGAP000610-RA) was shown to be an abundant transcript in the salivary gland. Saglin encodes for a secretory protein $(100 \mathrm{kDa})$ that has been shown to bind to the Plasmodium berghei sporozoite protein thrombospondin related anonymous protein (TRAP), and play a crucial role in salivary gland invasion by sporozoites, [24,25]. The presence of transcripts such as actin, chitin binding, cuticlar protein, myosin, laminin, tropomysin, tubulin, annexin, dynein light chain, connectin, dynactin, cadherin, and myosin muscle suggests that these genes play a significant housekeeping role in the A. gambiae salivary gland. 


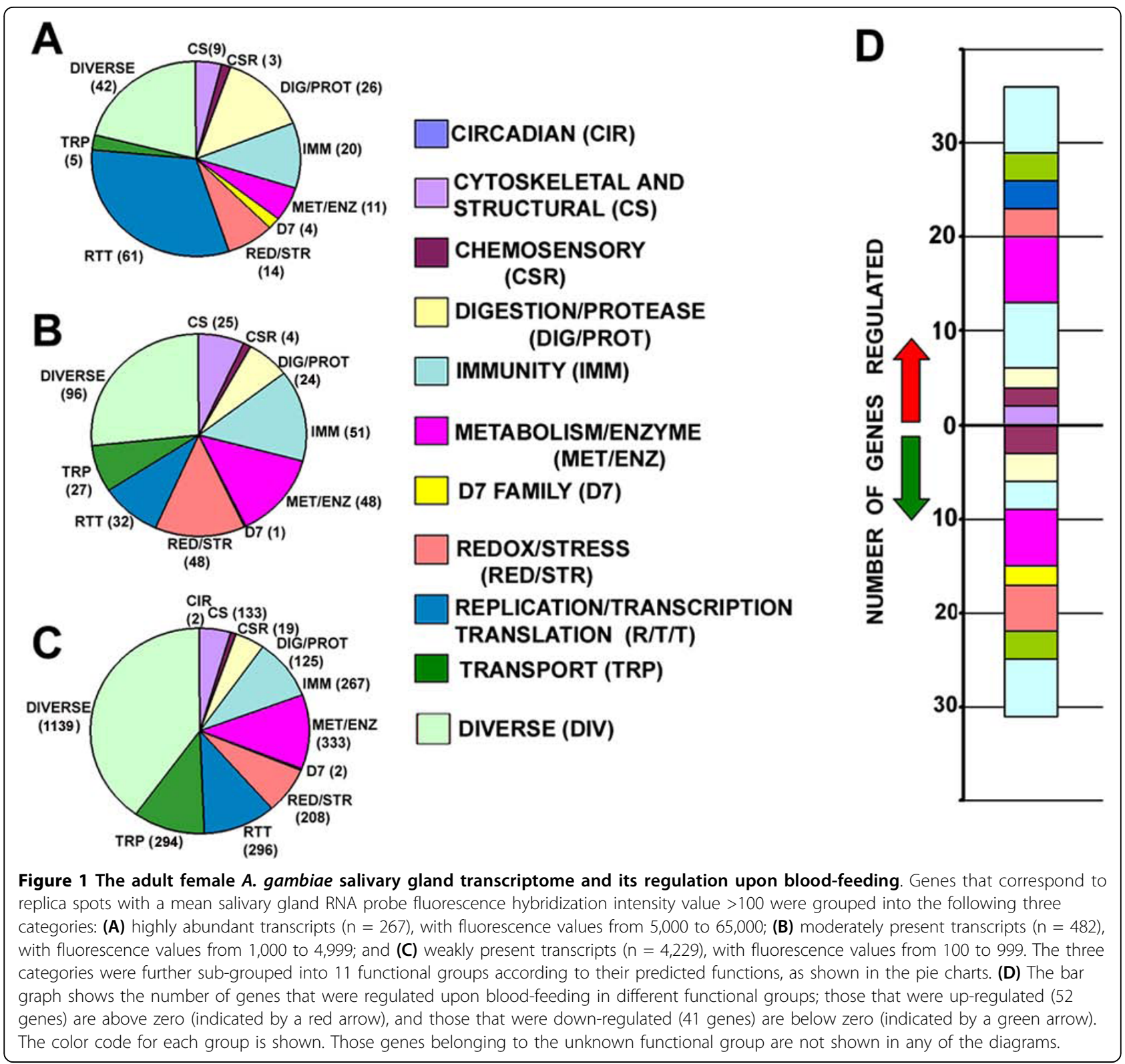

Genes involved in protein and sugar digestion

As many as 175 genes putatively involved in protein and sugar digestion were found to be transcribed in the $A$. gambiae salivary glands; 26 of these transcripts were highly abundant, 24 were moderately present and 125 were present at low levels (Additional file1). Many of these transcripts coding for proteases (peptidase C1, peptidase S1, peptidase S6, TRY2, TRY3, TRY4, TRY5, TRY6, TRY7, several serine proteases, carboxypeptidases, and aminopeptidases) and glycosidases (four maltase transcripts AGAP011939-RA, AGAP012401-RA, AGAP002102-RA, and AGAP008965-RA and chitinase transcript AGAP008061-RA) have a secretory signal peptide sequence.
Salivary gland glycosidases have been shown to be involved in the digestion of sugar, whereas the proteolytic enzymes could be involved in host-specific proteolytic events (clot prevention or the complement and coagulation cascades, or in the digestion of extracellular matrix components) that occur during the blood-feeding process. It is also possible that these proteolytic enzymes, which are secreted in the saliva, are ingested along with the blood, and might be involved in its digestion. Proteins encoded by transcripts that lack signal peptide sequences are most likely involved in housekeeping functions in the salivary gland or may be secreted by an alternative non-classical method [26]. The majority of these genes are also transcribed in the 
A. gambiae midgut and other tissues as well as during other developmental stages as has been demonstrated in earlier studies [27-29]. The proteolytic digestive enzymes in the midgut are mainly involved in the digestion of blood.

\section{Circadian and chemosensory genes}

Two circadian system-related genes, takeout and timeless, were weakly transcribed in the salivary gland. Takeout has been shown to act as a molecular link between circadian rhythm and feeding behavior in Drosophila melanogaster and A. gambiae [30,31], and timeless is a transcription factor that plays a major role in circadian regulation [32]. The timeless transcript has been identified previously in the A. gambiae female salivary gland [1]; however, we report for the first time the expression of takeout in this tissue.

Several genes with putative chemosensory functions, such as odorant binding proteins (OBPs), odorant receptors, antennal carrier protein, arrestins, gustatory receptors, and pheromone binding proteins, were transcribed in the A. gambiae salivary gland (3 were highly expressed, 4 were moderately expressed, and 19 were weakly expressed; see Additional file 1). OBPs are mainly localized in the mosquito head and within the antennae, where they function as carriers of odorants to the olfactory receptors [33]. The D7 family of proteins are distantly related to the OBP super-family, because of the conserved 6-cysteine and 10-cysteine residues and a characteristic fold structure [34]. However, the OBPs function as odorant carriers [33], whereas D7 proteins have been proposed to inhibit hemostasis by trapping agonists of hemostasis [35], and thereby facilitate bloodfeeding by hematophagous vectors (discussed in detail in the next section).

\section{D7 protein family genes}

The four highly transcribed members of the A. gambiae D7 family were the $D 7 r-1,2,3$ precursors (short form) and the D7 long form L2 (AGAP008279-RA) (fluorescence values above 5,000), whereas the $\mathrm{D} 7 \mathrm{r}-4,5$ precursors (short form) and another D7 long form L1 (AGAP008278-RA) were found to be only moderately/ weakly transcribed in the salivary glands (fluorescence values between 100 and 4,999) (see Additional file 1). The $D 7$ gene (coding for salivary biogenic-amine binding protein) was first identified in $A$. aegypti [36] as a major salivary gland secretory protein. The D7 protein exists in two forms: a long form $(\sim 30-35 \mathrm{kDa})$, which is found exclusively in mosquitoes and sand-flies, and the short forms $(\sim 15 \mathrm{kDa})$, which are found in other insects [37]. Five different D7-related (D7r1, 2, 3, 4, and 5) short forms and three D7 long forms have been identified in the A. gambiae adult salivary gland $[1,38]$. In 2006, Calvo et al. proposed that D7-related proteins from blood-sucking insects act as anti-hemostatic factors by trapping agonists of hemostasis. One short D7 protein from A. stephensi, hamadarin (D7r1), has been shown to inhibit the plasma contact system by preventing the activation of kallikrein by Factor XIIa [39]. The D7r1, 2, 3, 4 and D7 long forms have been shown to bind to the biogenic amines serotonin, histamine, and norepinephrine $[1,35]$. The crystal structures of one member of the D7 family, D7r4 (short form), and those of the ligand complexes were determined in order to elucidate the mechanisms governing its anti-hemostatic and anti-inflammatory properties [34]. It has been suggested that the ancestral D7 has originated from the proteins of the OBP family, which were adapted to bind small hydrophobic ligands $[34,40]$. We have further investigated the function of this family by looking at the changes in feeding and probing behavior of mosquitoes after silencing of the two D7 long forms, D7 L1 and D7 L2 (discussed below).

\section{Immunity- and stress-related genes}

Transcripts representing 338 immune genes (20 highly transcribed, 51 moderately transcribed, and 267 weakly transcribed) were found to be expressed in the A. gambiae female salivary glands (see Additional file 1). These genes included: lysozyme, gram negative bacteria binding protein (GNBP), the anti-microbial peptides cecropin and defensin, the NF $\kappa \mathrm{B}$ transcription factors Rel1 and Rel2, a c-type lectin (CTL), galectins, several fibrinogen binding proteins $(F B N)$, serpins, thioester containing proteins (TEP), a caspase, SOCS, TOLL, myd-88, a leucine rich receptor $(L R R)$, a scavenger receptor, a prophenoloxidase $(P P O)$, and others. Immune genes such as c-type lectins, prophenoloxidase activating enzymes, galectins, V5 allergens, and lysozyme were identified in the A. gambiae salivary gland $[1,16,19]$ and in another study, it was shown that GNBP, defensin, putative gal-lectin, and putative serine protease transcripts were up-regulated in the A. gambiae salivary gland after Plasmodium berghe $i$ infection [41]. In a more recent SAGE analysis of the $A$. gambiae salivary gland transcriptome upon $P$. berghei infection; 37 immune related genes were identified and four of them (defensin1, GNBP, serpin, cecropin2) were up-regulated during salivary gland invasion by the sporozoites [42].

Several of these immune genes encode secretory proteins, including GNBPs, several FBNs, the short antimicrobial peptides, PGRPs, chitinase, and lectins. Till date, little is known about the role of these immune genes in the A. gambiae female salivary gland, or whether they are directly involved in anti-Plasmodium or anti-microbial defenses. The secretory immune proteins may also be involved in protective immunity against microbes or other pathogens with which the mosquitoes come into direct contact during feeding. In the larval salivary gland, three defensins, three fibrinogen binding proteins, 
one CLIPB8, and four serine proteases have been detected [22]. Three different chitinase transcripts have been detected in A. gambiae larval salivary glands [22] and have been proposed to protect against pathogenic bacteria and fungi derived from the mosquitoes' diet [43]. Of the three different lysozyme transcripts detected in this study, one (AGAP007386-RA) was also detected in the salivary gland of larvae [22]. Lysozyme might be involved in preventing the growth of microbes in the sugar meal that is ingested with saliva and stored in the mosquito crop [44]. Most of these immune genes are also transcribed in other tissues, where they are involved in limiting bacterial and parasite growth [29,45-49]. Warr and coworkers [29] have shown that the cardia and anterior part of the midgut transcribe most of the antimicrobial peptides and other anti-Plasmodium factors.

Among the genes involved in oxidoreductive, antioxidant, and stress-related processes in A. gambiae, 270 transcripts were found to be present in the salivary glands ( 14 highly transcribed, 48 moderately transcribed, and 208 weakly transcribed) (see Additional file 1). This group was composed of several cytochrome P450 enzymes, glutathione s-transferase, cytochrome c oxidase, NADH ubiquinone, DNAJ homolog, oxidoreductase, animal heme peroxidase, thiorededoxin 1, mitochondrial inner membrane protein, and many others. Some of these transcripts have been identified earlier in salivary gland EST libraries or in other studies of different mosquito species $[1,16,19,50]$ and are involved in housekeeping functions of the salivary gland. Several transcripts coding for heat-shock proteins (HSPs) were found to be transcribed in the female salivary gland. HSPs belong to a family of proteins that function as chaperones or are involved in cellular defense against external stress from various sources [51].

\section{Metabolism and other enzyme genes}

As many as 392 transcripts (11 highly transcribed, 48 moderately transcribed, and 333 weakly transcribed) of genes putatively involved in metabolism and other enzymatic activities were found to be transcribed in the salivary gland of A. gambiae (see Additional file 1). Among the transcripts encoding putative secretory enzymes, three members of the $5^{\prime}$ nucleotidase gene family; an apyrase precursor (AGAP011971-RA), and two 5' nucleotidase precursors (AGAP011026-RA and AGAP003629-RA) were found to be transcribed in the adult salivary gland (see Additional file 1). The apyrase and one of the 5' nucleotidase precursors (AGAP011026RA) have been shown to be components of saliva $[23,52]$. The second $5 '$ nucleotidase precursor gene contains a secretory signal sequence, suggesting potential involvement in feeding. Of these three $5^{\prime}$ nucleotidase gene family transcripts, the AGAP011026-RA was highly expressed, and the other two were moderately expressed. Enzymes of this family facilitate the acquisition of blood meals by removing and degrading pharmacologically active ATP/ADP nucleotides from the site of the injury [53].

Silencing of an apyrase gene in the salivary gland of A. gambiae resulted in an increase in the mosquito probing time as well as increase in vitro platelet aggregation [9]. We have further investigated the function of this gene family by assaying changes in the feeding and probing behavior of mosquitoes after silencing the $5^{\prime}$ nucleotidase precursor transcript (AGAP011026-RA) (discussed below). Some of the metabolic enzymes with a signal peptide sequence include alpha amylase (AGAP002317RA) and alpha glucosidase (AGAP000862-RA), which are weakly transcribed in the female salivary glands. The transcript glycohydrolase (AGAP008124-RA), which is weakly transcribed in the A. gambiae salivary gland, also encodes a secretory protein and belongs to a large family with diverse functions reflecting their amino acid sequences: chitosanase, and NAD+ glycohydrolase, among many others [54].

\section{Genes of other functional groups}

Several genes involved in housekeeping functions and belonging to the replication-transcription-translation (389 genes in total) and transport functional groups (326 genes in total) were found to be transcribed in the A. gambiae salivary gland (see Additional file 1). In the replication-transcription-translation group, genes including several ribosomal proteins, histones, elongation factors, repressors, activators, proteasome subunits, and enzymes such as helicase, ligase, polymerase, DNA repair, ribonuclease, and many other enzymes were found to be transcribed. In the transport group, transcripts such as vesicle transport protein, solute carrier protein, ion transporter, ion channels, apolipophorin precursor, aquaporin water channel, and many others were found to be transcribed. Several transcripts (including cyclin, ferritin, zeelin 1, anophelin, trio, zinc finger domain, SG2, SG3, SG5, SG6 and SG10, many hypothetical precursors/peptides, and others) were found to be transcribed and were placed in the diverse group $(1,277$ transcripts in total) because of their assorted roles and various functions. The presence of vitellogenin precursor transcripts is likely to indicate contamination with fat body which is attached to the salivary glands.

A study recently showed that silencing of SG6 transcript results in an increased probing time and reduced feeding ability in A. gambiae female mosquitoes [11]. In this study we have investigated the function of the $S G 2$ transcript (the function of the SG2 protein is as yet unknown), by assaying changes in the feeding and probing behavior of mosquitoes after its depletion (discussed below). The SG1 protein precursor, a secretory protein, 
was found to be highly transcribed in the salivary gland; SG1 protein family members have molecular masses around $44 \cdot \mathrm{kDa}$ and do not exhibit significant similarities [55] to other proteins in the NCBI database, with the exception of the Anopheline distantly related TRIO protein (an abundant salivary gland gene) $[3,19]$, when analyzed by BLAST analysis. Transcripts of unknown function or with no homology to known protein were assigned to the group of unknown (1,609 transcripts in total). Further studies are required to link these transcripts with specific roles of salivation, feeding, blood digestion, and storage in A. gambiae.

\section{Regulation of A. gambiae salivary gland transcripts upon blood-feeding}

We have performed a microarray-based gene transcription analysis of the blood-feeding-regulated genes in the A. gambiae salivary gland. We compared the transcriptome of the A. gambiae salivary glands at $2 \mathrm{~h}$ after blood-feeding to salivary glands of unfed mosquitoes to identify salivary gland transcripts that are likely to play a role, either directly or indirectly, in the feeding process. Previous studies have shown that salivary gland proteins are rapidly depleted during feeding and that this depletion is proportional to the duration of feeding. Since blood fed mosquitoes are capable of taking a second blood-meal already at 24 hours after the first feeding, we hypothesized that the replenishment of the salivary gland proteins must initiate soon after feeding, and therefore selected a 2 hour time point after feeding to assay blood feeding-related changes in the salivary gland transcriptome $[23,56]$. Genome-wide microarray analysis of gene expression responses to blood feeding has been performed previously but for whole female $A$. gambiae mosquitoes [57], whereas our study is exclusively for the female salivary glands.

The resulting catalog of transcripts that exhibited differences in abundance prior and after blood feeding in the A. gambiae salivary gland is presented in Additional file 2 . In total, 93 transcripts were differentially regulated; 52 transcripts were more abundant and 41 transcripts were less abundant after blood-feeding (Figure 1D and see Additional file 2). Marinotti et al. showed in 2005 that some 4,924 transcripts, derived from whole mosquitoes displayed changes in abundance within 24 hour after blood-meal; 2,388 genes were up-regulated while 2,536 genes were down-regulated [57]. The salivary gland expressed transcripts that were significantly regulated by blood-feeding are presented in Table 1 (excluding the diverse and unknown groups).

The down-regulation of several female A. gambiae salivary gland transcripts can be attributed to the depletion of transcripts during protein translation or to the degradation of transcripts following blood-feeding. It is possible that their transcription may have been shut down because these transcripts were no longer required until the next blood-meal. Down-regulation of several $A$. aegypti salivary gland transcripts upon blood-feeding has been shown in a recent publication; the list of transcripts involved coded for secretory proteins, such as odorant binding protein, protease inhibitors, immune genes and other [58].

The secretory protein encoding salivary gland transcripts that displayed a lower abundance after bloodfeeding included two OBPs (OBP 10 and OBP 7), two D7 long-form precursors (L1 and L2), two aminopeptidases, a trypsin 6 precursor, a salivary lipase, a $5^{\prime}$ nucleotidase precursor, an apyrase, E1 protein, cecropin 3 , defensin 1, and a hypothetical 6.2 precursor. In earlier studies, several $O B P$ transcripts were shown to be down-regulated after blood-feeding in the head and antennae of $A$. gambiae [30] and in the salivary gland of A. aegypti [58]. In Marinotti et al., 2005, transcripts of several serine protease, aminopeptidase, odorant binding protein and transporter genes were found to be downregulated in whole female mosquitoes $24 \mathrm{hrs}$ after blood feeding. The OBP and odorant receptors are required by the female mosquitoes to sense host olfactory cues. The fact that the OBPs are not required after feeding until the next blood-meal may account for their lower transcript abundance. Both the secretory proteins aminopeptidases and trypsin 6 may be required for the digestion of host proteins or extracellular matrix components [59]. The apyrase and $5^{\prime}$ nucleotidase proteins are known to facilitate the acquisition of a blood meal by removing pharmacologically active nucleotides that are important for platelet aggregation at the site of the injury [53]. The D7 proteins inhibit hemostasis, and one short A. stephensi D7 protein, hamadarin, has been shown to inhibit the plasma contact system [39]. The secretory immune proteins like cecropin and defensin may provide protection against microbes or other pathogens that the mosquitoes encounter during feeding. In 2007, Rosinski-Chupin et al. showed that the immune peptide defensin 1 and cecropin 2 transcripts were upregulated in $P$. berghei infected $A$. gambiae salivary glands, thereby demonstrating that the salivary epithelium responds to the presence of pathogens [42].

Several transcripts were up-regulated after bloodfeeding, and those that encode putative secretory proteins included a trypsin 2 precursor, lysozyme, an $O B P$, an ATP binding protein, a vitellogenin precursor, and a $D N A J$ precursor. In contrast, two lysozyme transcripts were found to be down-regulated in whole female $A$. gambiae mosquitoes at 24 hours after blood-meal [57]. Lysozyme has been proposed to prevent bacterial growth in the sugar and blood meals $[1,16]$. The DNAJ family of proteins is involved in protein folding, protein 
Table 1 The female $A$. gambiae salivary gland expressed genes that are significantly differentially regulated upon blood-feeding

\begin{tabular}{|c|c|c|c|}
\hline GENE NAME & TRANS-CRIPT ID & FUNCTIONAL GROUP & $\log _{2}$ TRANSFORMED VALUE (MEAN) \\
\hline STATHMIN & E013307 & CS & 1.20 \\
\hline CHITIN BINDING PROTEIN & E022689 & CS & 1.08 \\
\hline PHEROMONE BINDING PROTEIN & E013682 & CSR & 1.60 \\
\hline ODORANT BINDING PROTEIN & E017475 & CSR & 0.75 \\
\hline ODORANT BINDING PROTEIN & E021953 & CSR & -0.79 \\
\hline ODORANT BINDING OBP10 & E012102 & CSR & -0.85 \\
\hline ODORANT BINDING OBP7 & E012251 & CSR & -0.90 \\
\hline TRYPSIN 2 PRECURSOR & E027737 & DIG/PROT & 1.11 \\
\hline PROTEASE PRECURSOR & E018532 & DIG/PROT & 0.80 \\
\hline AMINOPEPTIDASE N & E002729 & DIG/PROT & -0.82 \\
\hline AMINOPEPTIDASE & E012865 & DIG/PROT & -1.07 \\
\hline TRYPSIN 6 PRECURSOR & E018354 & DIG/PROT & -1.09 \\
\hline D7 L2 PRECURSOR ALLERGEN AED A 2 & E018280 & D7 FAMILY & -1.75 \\
\hline D7 L1PRECURSOR ALLERGEN AED A 2 & E023833 & D7 FAMILY & -2.01 \\
\hline RELISH & E020147 & IMMUNE & 1.14 \\
\hline REL1 & E011101 & IMMUNE & 0.90 \\
\hline CASPS5 & E021365 & IMMUNE & 0.82 \\
\hline LYSOZYME c-7 & E018439 & IMMUNE & 0.78 \\
\hline LECTIN & E010670 & IMMUNE & -0.75 \\
\hline E1 PROTEIN Def2/Der2 ALLERGEN & E017011 & IMMUNE & -0.80 \\
\hline CECROPIN B & E011995 & IMMUNE & -0.96 \\
\hline DEFENSIN & E015621 & IMMUNE & -1.04 \\
\hline ETHANOLAMINE PHOSPHATE TRANSFERASE & E012337 & MET/ENZ & 1.45 \\
\hline ELONGATION OF VERY LONG CHAIN FATTY ACIDS & E010068 & MET/ENZ & 1.40 \\
\hline L 3 PHOSPHOSERINE PHOSPHATASE & E016587 & MET/ENZ & 1.02 \\
\hline LIPOAMIDE ACYLTRANSFERASE & E024823 & MET/ENZ & 0.94 \\
\hline PYRIDOXAL PHOSPHATE PHOSPHATASE & E024098 & MET/ENZ & 0.89 \\
\hline PROTEIN KINASE & E012934 & MET/ENZ & 0.89 \\
\hline DIPEPTIDYL PEPTIDASE IV & E010468 & MET/ENZ & 0.75 \\
\hline GLYCEROL 3 PHOSPHATE DEHYDROGENASE & E017587 & MET/ENZ & -0.79 \\
\hline ISOCITRATE DEHYDROGENASE [NAD] SUBUNIT & E010852 & MET/ENZ & -0.80 \\
\hline SERINE PYRUVATE AMINOTRANSFERASE & E015996 & MET/ENZ & -1.09 \\
\hline CYTOCHROME P450 & E026706 & REDOX/STRESS & 1.57 \\
\hline CYTOCHROME P450 & E029062 & REDOX/STRESS & 1.51 \\
\hline DNAJ & E022059 & REDOX/STRESS & 1.46 \\
\hline GLUTATHIONE S TRANSFERASE & E012678 & REDOX/STRESS & -0.78 \\
\hline COX5B CYTOCHROME C OXIDASE & E011122 & REDOX/STRESS & -0.86 \\
\hline MITOCHONDRIAL UBIQUINOL CYTOCHROME C & E017699 & REDOX/STRESS & -0.92 \\
\hline UBIQUINOL CYTOCHROME C REDUCTASE & E021887 & REDOX/STRESS & -0.97 \\
\hline OXIDOREDUCTASE & E021713 & REDOX/STRESS & -1.04 \\
\hline CCR4 ASSOCIATED FACTOR 2 & E010439 & RTT & 1.68 \\
\hline MEDIATOR OF RNA POLYMERASE ॥ & E021242 & RTT & 1.49 \\
\hline SPLICING FACTOR ARGININE/SERINE RICH & E016046 & RTT & 1.27 \\
\hline SUCCINATE DEHYDROGENASE [UBIQUINONE] & E019261 & TRP & 1.60 \\
\hline VACUOLAR H+-TRANSPORTING C SUBUNIT & E013400 & TRP & 1.03 \\
\hline$\overline{\text { ADP ATP CARRIER ADP/ATP TRANSLOCASE }}$ & E020278 & TRP & -0.87 \\
\hline
\end{tabular}


Table 1 The female $A$. gambiae salivary gland expressed genes that are significantly differentially regulated upon blood-feeding (Continued)

\begin{tabular}{llll}
\hline ATP SYNTHASE B CHAIN MITOCHONDRIAL & E012069 & TRP & -0.94 \\
\hline ADP ATP CARRIER ADP/ATP TRANSLOCASE & E014881 & TRP & -1.70
\end{tabular}

The ENSEMBL transcript IDs have been shortened by replacing the first 12 characters of ENSANGT00000 with "E". The genes are sorted into different functional groups according to their predicted functions (CS: cytoskeletal and structural; CSR: chemosensory; PROT/DIG: proteolytic digestion; D7 family: D7 family; IMM: immunity; MET/ENZ: metabolism and other enzymes; RED/STR: redox/stress; R/T/T: replication/transcription and translation; TRP: transport). The mean log ${ }_{2}^{-}$ transformed-fold transcript abundance ratio is shown in column 4.

transport, and the cellular response to stress [60]. The exact role of these genes in the salivary gland and their function in the blood-feeding process are still not clear. We have further investigated the function of some of these differentially regulated genes by looking at how they influence the mosquito feeding and probing behavior upon depletion.

\section{Functional analysis of salivary gland gene implication in blood-feeding and probing behavior}

To identify putative components of the A. gambiae salivary gland that play a role in blood-feeding, we performed transient RNAi gene-silencing assays on 10 salivary gland transcribed genes and studied the effect of this treatment on mosquito feeding behavior on a vertebrate host (Figure 2A). In our first assay, instead of assaying probing time of individual mosquitoes we determined the blood feeding capacity (4 days after dsRNA injections) as a measure of their feeding status after 20 minutes exposure to the vertebrate host since probing time may not be the only determining factor of feeding capacity, nor an exclusive indicator for a salivary gland function that facilitates feeding. It is conceivable to hypothesize that the amount of ingested blood is dependent on probing time, feeding time and the flow rate of blood which may depend on its viscosity. We specifically compared blood-feeding capacity between gene silenced and control group mosquitoes that had been injected with GFP dsRNA according to previously established methodology [30]. Four of these genes, two D7 long forms (D7L1 and D7L2), one salivary gland peroxidase 5B (AGAP010735-RA), and one 5' nucleotidase (AGAP011026-RA), were selected because of their predicted anti-inflammatory, vasodilatory, and anti-platelet activities, respectively $[39,53,61]$ as well as their downregulation after blood-feeding (see Additional file 2). A salivary gland lipase enzyme (AGAP005822-RA) whose function is not clear and down-regulated after blood-feeding (see Additional file 2) was selected for functional analysis. Five other genes were selected based on their predicted involvement in anti-hemostatic processes and for representing major A. gambiae salivary gland secretory proteins: anophelin/cEF (AGAP008004RA), which acts as an $\alpha$-thrombin inhibitor to prevent blood coagulation [62]; a salivary $30 \mathrm{kDa}$ protein
(AGAP009974-RA), a member of the aegyptin family, and whose members have been shown to bind to collagen and block platelet adhesion to collagen [63,64]; an SG2 precursor (AGAP006506-RA) with unknown function; and salivary mucin (AGAP001192-RA) and TRIO (AGAP001374-RA), which are two highly abundant salivary gland transcripts in A. gambiae $[1,19,62]$ (see Additional file 1). In Drosophila melanogaster, the TRIO protein has been shown to be involved in the cytoskeletal rearrangements necessary for cell migration [65]; however, its exact function in A. gambiae is not known.

RNAi-mediated gene silencing assays in adult mosquitoes depend on the direct injection of dsRNAs into the hemolymph and we used the dsRNA injection procedure established by Boisson et al., 2006 (see Materials and Methods) and monitored gene silencing efficiency in the salivary glands 4 days after dsRNA injections (Figure 2B). Silencing efficiency for the selected genes ranged from $19 \%$ to $46 \%$ (Figure $2 \mathrm{~B}$ and see Additional file 3 ). The effect of gene silencing on the mosquito's bloodfeeding capacity is shown in Figure $2 \mathrm{~A}$, and the statistical analysis of the data is presented in Additional file 4.

Only mosquitoes in which $D 7 L 2$, anophelin, peroxidase $5 B$, or $S G 2$ precursor was silenced displayed a significantly altered feeding capacity (by $\sim 15-22 \%$ ) when compared to the GFP dsRNA-injected control mosquitoes (Figure 2A). The D7 proteins have been shown to bind biogenic amines such as serotonin and histamine, which may antagonize the vasoconstriction, platelet aggregation, and pain induction that occur during feeding [34]. The lower feeding capacity observed after the silencing of D7L2 strongly supports the involvement of its encoded protein (and of other members of this family) in the blood-feeding process. This protein may act as an anti-hemostatic factor by trapping agonists of hemostasis, as suggested by Calvo et al. (2006). The salivary peroxidase $5 \mathrm{~B}$ is known to have vasodilatory activity. Therefore, we hypothesize that the lower bloodfeeding capacity of peroxidase-silenced mosquitoes is due to the resulting increased vasoconstriction and diminished blood-flow at the probing site. The anophelin gene encodes an $\alpha$-thrombin inhibitor that prevents blood coagulation during the blood-feeding process. Depletion of the anophelin protein is expected to decrease the blood-flow at the site of probing; an effect 


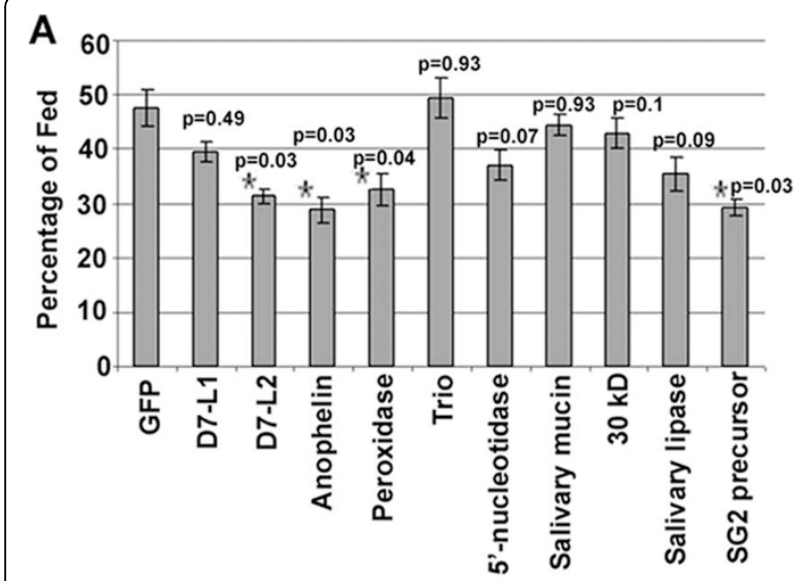

B

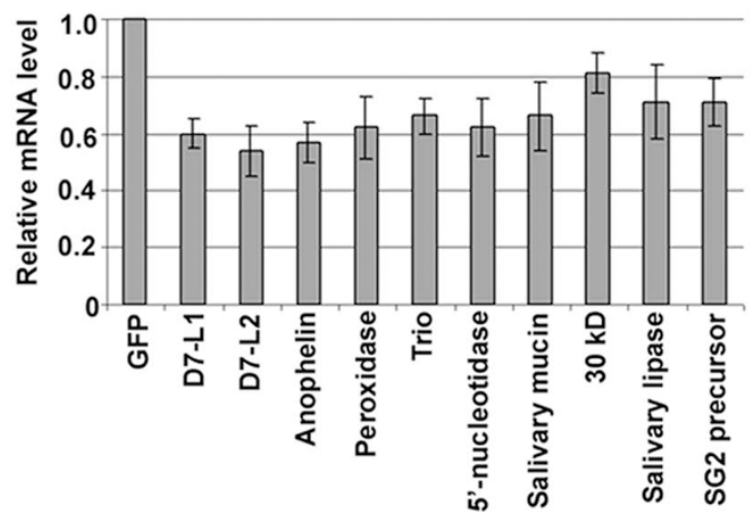

Figure 2 Implication of salivary gland genes in blood-feeding capacity. A. The percentage of gene-silenced mosquitoes that fed on a mouse after gene-specific silencing through RNAi compared to the GFP dsRNA injected control mosquitoes. Data were pooled from six replicates of 25 mosquitoes each. Genes displaying significant capacity to alter blood feeding propensity upon silencing are indicated with an asterisk, and the p-values are shown for each gene (from the Mann-Whitney test). The error bars indicate the standard error. B. Determination of RNAi-mediated gene silencing efficiency, by qRT-PCR at 4 days after dsRNA injection. The cDNA templates were normalized using the AgS7 gene specific primers The graph shows the relative transcript abundance of each gene after knockdown, as compared to its abundance in the GFP dsRNAtreated control mosquitoes (set to 1.0). The error bars indicate the standard error.

that may account for the lower feeding propensity of the anophelin-silenced mosquitoes. Silencing of a small secretory peptide SG2 precursor also resulted in a decreased blood-feeding capacity, although its role during blood-feeding is not yet clear. In earlier studies, silencing of a salivary apyrase gene (involved in the inhibition of platelet aggregation in A. gambiae) and a SG6 precursor led to an increased probing time and decreased blood-feeding ability in A. gambiae mosquitoes $[9,11]$. However, further studies are needed to characterize the biological properties of this unknown peptide SG2.
The D7L1 and 5' nucleotidase genes are known to have anti-inflammatory and anti-platelet activity, respectively; however, the silencing of these two genes resulted in only an $8-10 \%$ decrease in their blood-feeding capacity (when compared to the GFP control). The lack of any significant effects on feeding after silencing of the remaining six genes (D7L1, TRIO, 5' nucleotidase, salivary mucin, salivary lipase, and $30 \mathrm{kDa}$ ) may be related to the relatively low silencing efficiency obtained in the salivary gland as well as to the presence of unknown factors that perform redundant functions in the mosquito salivary gland.

In a second set of assays we determined the effect of salivary gland transcript depletion on the mosquitoes probing time (Figure 3), as a measure of time, or interval, between the insertion of mouthparts into the host skin and the initiation of blood ingestion, according to methodology established in previous studies $[9,11]$. Of the six genes that were selected for probing time assays, depletion of D7L2, anophelin, peroxidase and SG2 precursor (Figure 2A) resulted in decreased blood feeding capacity and as well as increased probing time (Figure 3). These results strongly suggest a vital role in the bloodfeeding process for these genes. Depletion of the $5^{\prime}$ nucleotidase resulted in a significantly longer probing time (Figure 3 ) but not a significantly altered bloodfeeding capacity (Figure 2A). This indicates that bloodfeeding capacity is not exclusively dependent on probing time.

The depletion of TRIO ( $\mathrm{p}=0.7)$ did not result in any significant changes either in blood-feeding behavior or probing time.

\section{Conclusions}

The mosquito salivary glands play essential roles in blood-feeding and pathogen transmission. We have used a genome-wide microarray approach to characterize the A. gambiae salivary gland transcriptome, which corresponds to 4,978 genes (Figure 1), thereby extending earlier work based on cDNA/EST library clones $[1,21,57]$. Through the use of a full-genome microarray, we have obtained information on salivary gland transcript abundance and assessed the impact of blood feeding on salivary gland gene transcript abundance. The 93 transcripts showing significant differential abundance between the salivary glands of unfed and blood-fed female mosquitoes were mainly involved in metabolic, immunity, and oxidative stress-related processes (Figure 1D). It will be interesting to know whether the salivary gland expressed immune genes are involved in the interaction with, or killing of, the Plasmodium sporozoites. Interestingly, the majority of the secretory salivary gland-expressed transcripts displayed a lower abundance after blood-feeding, suggesting that their products may 
have been employed for protein synthesis during feeding and eventually degraded, or their transcription had been shut down. The lower blood-feeding capacity and increased probing time of mosquitoes upon silencing of the D7L2, anophelin, peroxidase $5 B, S G 2$ precursor, and $5^{\prime}$ nucleotidase genes is consistent with their role as anti-hemostatic factors (Figure 2A and Figure 3) [1,62].

A better understanding of salivary gland gene expression and function can contribute to the development of malaria control strategies based on blocking the Plasmodium parasite in genetically modified mosquitoes or transmission blocking vaccines that could inhibit infection of the glands [66]. Furthermore, our studies indicate that the salivary glands of Anopheles mosquitoes express a variety of pharmacologically active substances that may be of value for designing novel anti-thrombotic or anti-platelet drugs for the treatment of cardiovascular disorders.

\section{Methods}

\section{Rearing of $A$. gambiae mosquitoes}

A. gambiae Keele strain mosquitoes were reared at $27^{\circ} \mathrm{C}$ in $70 \%$ humidity, and adults were maintained on a $10 \%$ sucrose solution on a 12-h light/dark cycle, according to standard rearing conditions [67].
RNA isolation and quantitative real-time PCR (qRT-PCR) RNA was extracted and quantified (in triplicate samples) from dissected salivary glands ( 80-100) using an RNeasy kit (Qiagen, Valencia, California, USA) according to standard methodology [68]. The qRT-PCR assays were performed as previously described [68], and the ribosomal protein $\mathrm{S} 7$ gene was used for normalization of the cDNA templates. The gene silencing efficiency (see below) was calculated according to the standard $\mathrm{E}^{\Delta \Delta \mathrm{Ct}}$ method [69].

\section{Microarray analysis}

A. gambiae mosquitoes were allowed to feed for $20 \mathrm{~min}$ on Swiss Webster strain mice that had been anesthetized with a ketamine solution. For the microarray transcription analysis, approximately 100 salivary glands in triplicate were dissected $2 \mathrm{~h}$ after blood feeding (from both blood-fed and unfed mosquitoes). The blood-fed mosquitoes were not provided sugar solution for $2 \mathrm{hrs}$ after blood-feeding, after which the salivary glands were dissected. The control unfed mosquitoes were treated in the same way. It should be noted that the triplicate assays were performed on different cohorts and generations. For the transcriptomic studies involving blood-fed regulated salivary gland gene expression, probes

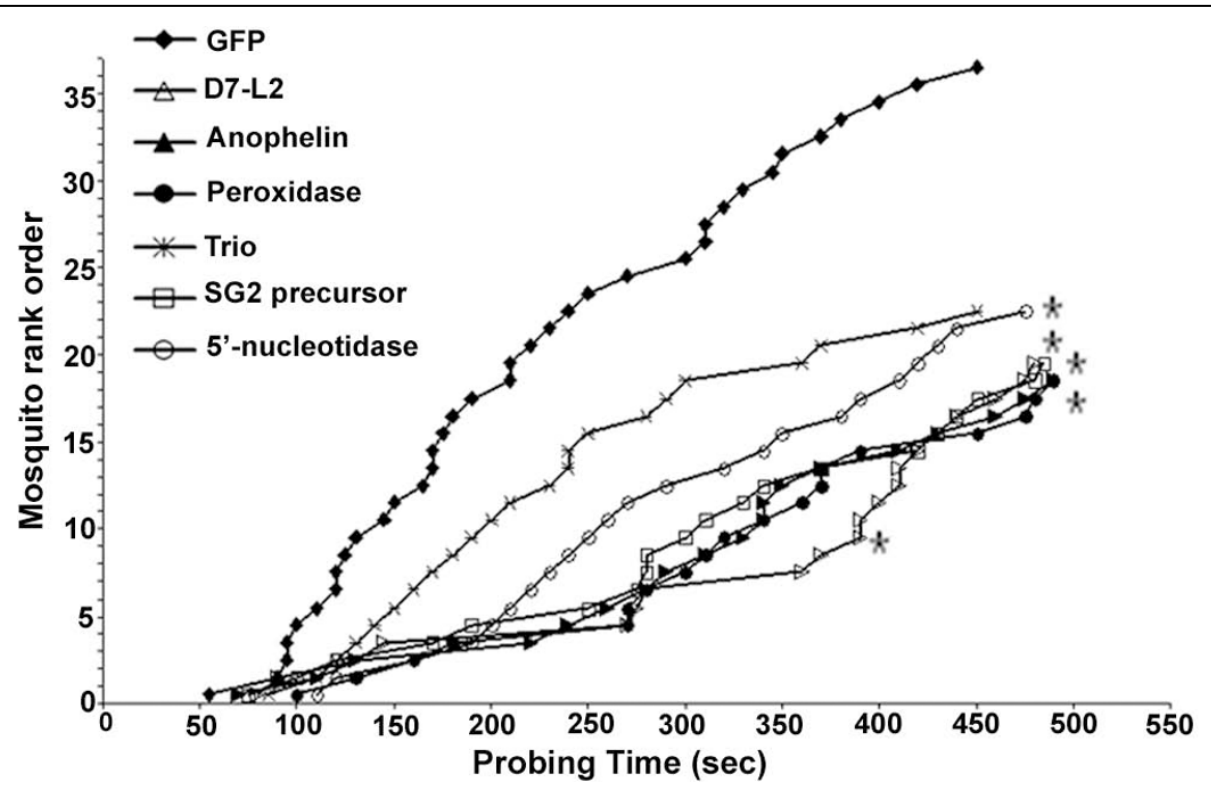

Figure 3 Functional implication of salivary gland genes in the probing behavior of mosquitoes. Probing time spent by gene silenced mosquitoes (depleted of D7-L2, anophelin, peroxidase, trio, SG2 precursor and 5' nucleotidase transcripts), and GFP dsRNA injected control mosquitoes, from the insertion of mouthparts into the mouse skin and the first sign of blood within the midgut. Four days after dsRNA injection, individual mosquitoes were exposed to an anesthetized mouse for 500 seconds. Probing times were only measured for those mosquitoes that initiated ingestion of blood within the 500 seconds interval. GFP $(n=37)$, D7-L2 $(n=20 ; p=0.002)$, anophelin $(n=19 ; p=0.012)$, peroxidase $(n=19 ; p=0.007)$, trio $(n=23 ; p=0.7), S G 2$ precursor $(n=20 ; p=0.02), 5^{\prime}$ nucleotidase $(n=23 ; p=0.05)$, where $n$ is the total number of mosquitoes tested for each gene and $p$ value is determined by the Mann-Whitney test. Results from three independent sets of experiments are shown in the graph. The rank order (the cumulative number of mosquitoes from different replicas that completed their probing within this time-interval) was plotted against the time. 
prepared from the RNA of salivary glands from bloodfed mosquitoes (labeled with Cy-5-dUTP fluorescent nucleotides) were co-hybridized with probes prepared from the RNA (labeled with Cy-3-dUTP fluorescent nucleotides) obtained from salivary glands of unfed mosquitoes. An Agilent custom-made 60-mer oligonucleotide microarray representing the full A. gambiae transcriptome was used for the assays. The Cy-5- and Cy-3-labeled probes were synthesized using the Low RNA Input Fluorescent Linear Amplification Kit from Agilent Technologies (Santa Clara, California, USA), and the slides were scanned using a GenePix 7000 autoloader scanner (Axon Instruments), as previously described in Dong et al., 2006. Scanning and data analyses were performed as previously described, with a signal cut-off intensity of 100 to remove low-intensity/poorly hybridized spots from the analysis. Loc-Fit normalization (LOWESS) was performed independently for each data set. The TMEV software, available online (http://www. tm4.org/mev/), was then used for t-test analysis at a significance level of $\mathrm{p}<0.05$, to evaluate the variability between biological replicates. Only transcripts that had signal values above or below a $\log _{2}$ cutoff value of \pm 0.75 were considered significantly regulated with bloodfeeding and used for further analysis (Figure 1D). If a particular gene was not regulated in the same direction in all the three biological replicates, it was considered to be non-significantly regulated. The GEO-NCBI accession numbers are: GSM573605, GSM573606 and GSM573607.

For the determination of the global A. gambiae female salivary gland transcriptome, the microarray spot hybridization fluorescence intensities were used as an indicator of transcript abundance/expression level, since each spot contained a similar amount of nucleic acid. First, the spot fluorescence intensity values from the three replicate assays were averaged for each spot and then for each gene (some genes were represented by multiple spots), generating a list of transcripts that were expressed in the A. gambiae female salivary gland. Transcripts were then categorized in groups on the basis of their relative transcript abundance, as measured by the mean fluorescence value (at $635 \mathrm{~nm}$ ) of each transcript. This analysis produced the following three groups: i) highly abundant transcripts (fluorescence intensity of $5,000$ to the maximum threshold of 65,000$)$, ii) moderately expressed transcripts $(1,000$ to 4,999$)$ and iii) poorly expressed transcripts (100 to 999) (listed as three different Excel spreadsheets in Additional file 1). The average fluorescence values at both 635 and $532 \mathrm{~nm}$ from the three GPR files (Genepix) are listed in Additional file 1 , for direct comparison of each transcript before and after blood-feeding. The lists of genes were then further sub-grouped into different functional groups according to their known functions (Figure 1). The microarray validation by independent quantitative real-time PCR (qRT-PCR) on some of the genes was performed (data not shown) as described in our earlier publications $[68,70]$. The validation data showed a high degree of correlation between the microarray and qRTPCR values (Pearson correlation coefficient, $\mathrm{p}=0.91$; best-fit linear regression, $R^{2}=0.84$; slope of the regression line $=0.85$ ).

\section{RNAi gene-silencing assays in adult mosquitoes}

RNA interference (RNAi) assays in adult female mosquitoes were performed according to established RNAi methodology [71], using GFP dsRNA as the control. At least three independent RNAi-mediated gene-silencing assays were performed for each gene on different days, with two replicates each time; 35-40 mosquitoes were injected for each replicate, and 25 randomly selected surviving mosquitoes from each replicate were used for further blood-feeding assays. It should be noted that the triplicate assays were conducted on different days, and the mosquitoes were from different cohorts/generations.

To silence the transcripts in the salivary glands, at least 8-9 times more dsRNA ( 1.6-1.8 $\mu$ g per mosquito) than normal $(\sim 0.2 \mu \mathrm{g})$ was injected [9] in order to obtain a better silencing efficiency in this body part, which is less accessible to diffusion of dsRNA from the hemolymph. The primer sequences of the selected genes and the GFP used to generate dsRNA are listed in Additional file 5 . For gene silencing verification by qRT-PCR, 40-50 mosquitoes were injected with dsRNA, and the salivary glands were dissected 4 days later. The ribosomal protein $\mathrm{S} 7$ gene was used for normalization of the cDNA templates (primer sequences are provided in Additional file 5). The fold difference in transcript abundance levels (the silencing efficiency) after silencing was calculated according to the standard $\mathrm{E}^{\Delta \Delta \mathrm{Ct}}$ method [69]. The primers used for silencing verification are presented in Additional file 6.

\section{Blood-feeding assays}

To study the blood-feeding propensity upon gene silencing, mosquitoes were exposed to anesthetized (with ketamine solution) Swiss Webster mice 4 days after the dsRNA injections. The mosquitoes were allowed to feed for $20 \mathrm{~min}$, after which we scored the number of mosquitoes that had fed. Two mice were required for each feeding experiment (GFP control and experimental), and were used simultaneously by placing each mouse with its head over one cage and its tail over the other. Every $5 \mathrm{~min}$, the positions of the mice were flipped (with minimum interruption) to ensure that the two mosquito sets drew blood from the identical body parts of the two mice. For statistical analysis of the gene silencing 
phenotypes (blood-feeding propensity) with respect to GFP control, a Mann Whitney test was used, as shown in our earlier publications [68,72]; the resulting p-values are given in Figure 2A and Additional file 4.

\section{Probing assays}

Three days-old adult female mosquitoes were injected with dsRNA as described above and their probing time was assayed four days later. The mosquitoes were starved from sugar for 4-5 hours before conducting the probing time measurements as described in Lombardo et al., 2009. A single mosquito was transferred in a small cage and allowed to rest for $30 \mathrm{~min}$ before being offered an anesthetized (with ketamine solution) Swiss Webster mouse. Probing time is defined as the time taken from the initial insertion of the mouthparts in the skin until the initial engorgement of blood $[9,11,73]$. If the mosquito terminates the probing unsuccessfully and tries again elsewhere, the second probing time is progressively added to the first one until blood is ingested. The time between two probings (interprobing time), is not included. The assay was conducted for 500 seconds for each mosquito. Three independent sets of dsRNA injections for probing time were performed for each of the six genes and were compared to the probing time of GFP dsRNA injected control mosquitoes. The results from all replica assays were pooled and the rank order of the mosquitoes (the cumulative number of mosquito pooled from different replicas that completes their probing, at any particular time within the 500 seconds period) was plotted against time (seconds), as performed in earlier studies $[9,11]$. The data was then analyzed by the Mann-Whitney test for statistical significance as described in Lombardo et al., 2009. The total number of mosquitoes tested (n) and the resulting $\mathrm{p}$-values for each silenced transcript and GFP dsRNA injected control are shown in Figure 3 legend.

\section{Additional material}

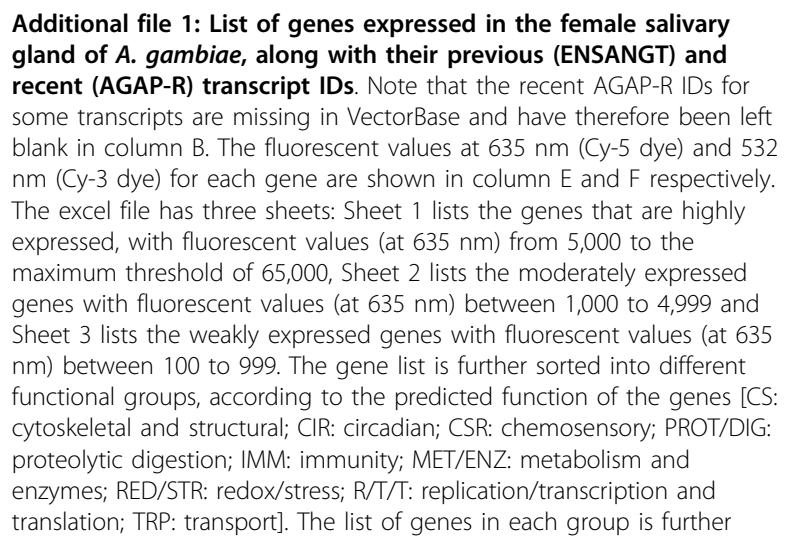

sorted into descending order of the fluorescent value at $635 \mathrm{~nm}$ (column E).

Additional file 2: List of genes that are regulated upon bloodfeeding in the female $A$. gambiae salivary gland, along with their ENSANGT and more recent AGAP-R transcript IDs. Transcripts lacking AGAP-R IDs are only indicated with the ENSANT transcript ID. Genes are only listed if they display significant differential regulation between fed and unfed mosquitoes, at a $\log _{2}$ fold ratio above or below the \pm 0.75 threshold. Predicted functional groups classification for genes are also presented [CS: cytoskeletal and structural; CIR: circadian; CSR: chemosensory; PROT/DIG: proteolytic digestion; IMM: immunity; MET/ ENZ: metabolism and enzymes; RED/STR: redox/stress; R/T/T: replication/ transcription and translation; TRP: transport].

Additional file 3: Gene silencing efficiency of the 10 selected genes The gene transcript abundance in GFP dsRNA treated mosquitoes was set to 1.0, and the corresponding percentage silencing was determined by qRT-PCR. The AgS7 gene was used for normalization of CDNA templates. The standard error values are shown.

Additional file 4: The blood-feeding propensity of mosquitoes in gene silenced mosquitoes. Ten salivary gland expressed genes were individually silenced in mosquitoes, and the mosquitoes were allowed to feed on blood, 4 days after dsRNA injections. The percentages of mosquitoes that feed ("Fed") were scored and are shown along with their standard error values. The p-value from statistical analysis of Mann Whitney Test is also shown.

Additional file 5: Primers used for synthesis of dsRNAs for RNAi gene silencing assays. The first 20 bases in bold correspond to the T7 polymerase promoter site. The transcript ID numbers (AGAP-RA from VectorBase) are also shown for each gene. The list also includes the sequences of GFP primers used for generating dsRNA and the $A$. gambiae S7 primer (used for standardization of CDNA templates).

Additional file 6: Primers used for verification of RNAi silencing. The sense primers were newly designed (VERI Sense), and the antisense primers used were the same as those used for making the corresponding dsRNAs. The transcript ID numbers (AGAP-RA from VectorBase) are also shown for each gene.

\section{Abbreviations}

GFP: green fluorescent protein; qRT-PCR: quantative real-time polymerase chain reaction; RNAi: RNA interference; OBP: odorant binding proteins; dsRNA: double-strand RNA.

\section{Acknowledgements}

We thank the microarray core facility and the insectary personnel at the Johns Hopkins Malaria Research Institute. We also thank Dr. Fotis C. Kafatos and Dr. Jose M. Ribeiro for their discussions and fruitful suggestions and Dr. Deborah McClellan for editorial assistance. This work was supported by the Ellison Medical Foundation, the National Institutes of Health/National Institute for Allergy and Infectious Disease 1R01A1061576, the United Nations Development Program/World Bank/World Health Organization Special Program for Research and Training in Tropical Diseases, and the Johns Hopkins School of Public Health.

\section{Author details}

'W. Harry Feinstone Department of Molecular Microbiology and Immunology, Bloomberg School of Public Health, Johns Hopkins University, 615 N Wolfe Street, Baltimore, MD 21205-2179, USA. ²Department of Pathobiological Sciences, University of Wisconsin-Madison, 1656 Linden Drive, Madison, WI 53706, USA. Imperial College London, Division of Cell and Molecular Biology, Faculty of Natural Sciences, South Kensington Campus, London, UK. ${ }^{4}$ Laboratory of Malaria and Vector Research, NIAID, National Institutes of Health, Rockville, Maryland 20852, USA.

\section{Authors' contributions}

SD and AR conducted the microarray and gene silencing assays and SD contributed to the writing of the manuscript. YJC, AM and JGV performed preliminary and confirmatory analyses and assays and edited the manuscript. 
GD designed the experiments and the oligonucleotide microarrays and contributed to the writing of the manuscript. All authors read and approved the final manuscript.

Received: 1 May 2010 Accepted: 14 October 2010 Published: 14 October 2010

\section{References}

1. Arca B, Lombardo F, Valenzuela JG, Francischetti IM, Marinotti O, Coluzzi M, Ribeiro JM: An updated catalogue of salivary gland transcripts in the adult female mosquito, Anopheles gambiae. J Exp Biol 2005, 208:3971-3986.

2. Bolognesi ML, Minarini A, Budriesi R, Cacciaguerra S, Chiarini A, Spampinato S, Tumiatti V, Melchiorre C: Universal template approach to drug design: polyamines as selective muscarinic receptor antagonists. $J$ Med Chem 1998, 41:4150-4160.

3. Lanfrancotti A, Lombardo F, Santolamazza F, Veneri M, Castrignano T, Coluzzi M, Arca B: Novel CDNAs encoding salivary proteins from the malaria vector Anopheles gambiae. FEBS Lett 2002, 517:67-71.

4. Monteiro RQ: Targeting exosites on blood coagulation proteases. An Acad Bras Cienc 2005, 77:275-280.

5. Baldacci $P$, Menard R: The elusive malaria sporozoite in the mammalian host. Mol Microbiol 2004, 54:298-306.

6. Frevert U, Engelmann S, Zougbede S, Stange J, Ng B, Matuschewski K, Liebes L, Yee $\mathrm{H}$ : Intravital observation of Plasmodium berghei sporozoite infection of the liver. PLOS Biol 2005, 3:e192.

7. Ribeiro JM: Vector salivation and parasite transmission. Mem Inst Oswaldo Cruz 1987, 82(Suppl 3):1-3.

8. Stark KR, James AA: Anticoagulants in vector arthropods. Parasitol Today 1996, 12:430-437.

9. Boisson B, Jacques JC, Choumet V, Martin E, Xu J, Vernick K, Bourgouin C: Gene silencing in mosquito salivary glands by RNAi. FEBS Lett 2006, 580:1988-1992.

10. Ribeiro JM, Rossignol PA, Spielman A: Role of mosquito saliva in blood vessel location. J Exp Biol 1984, 108:1-7.

11. Lombardo F, Ronca R, Rizzo C, Mestres-Simon M, Lanfrancotti A, Curra C, Fiorentino G, Bourgouin C, Ribeiro JM, Petrarca V, et al: The Anopheles gambiae salivary protein gSG6: an anopheline-specific protein with a blood-feeding role. Insect Biochem Mol Biol 2009, 39:457-466.

12. Golenda CF, Klein T, Coleman R, Burge R, Ward RA, Seeley DC: Depletion of total salivary gland protein in blood-fed Anopheles mosquitoes. J Med Entomol 1995, 32:300-305.

13. Siriyasatien $P$, Tangthongchaiwiriya $K$, Kraivichian $K$, Nuchprayoon $S$, Tawatsin A, Thavara U: Decrease of mosquito salivary gland proteins after a blood meal: an implication for pathogenesis of mosquito bite allergy. J Med Assoc Thai 2005, 88(Suppl 4):S255-S259.

14. Belkaid Y, Valenzuela JG, Kamhawi S, Rowton E, Sacks DL, Ribeiro JM: Delayed-type hypersensitivity to Phlebotomus papatasi sand fly bite: An adaptive response induced by the fly? Proc Natl Acad Sci USA 2000, 97:6704-6709.

15. Valenzuela JG, Belkaid Y, Garfield MK, Mendez S, Kamhawi S, Rowton ED, Sacks DL, Ribeiro JM: Toward a defined anti-Leishmania vaccine targeting vector antigens: characterization of a protective salivary protein. J Exp Med 2001, 194:331-342.

16. Arca B, Lombardo F, de Lara CM, della TA, Dimopoulos G, James AA, Coluzzi M: Trapping cDNAs encoding secreted proteins from the salivary glands of the malaria vector Anopheles gambiae. Proc Natl Acad Sci USA 1999, 96:1516-1521.

17. Arca B, Lombardo F, Francischetti IM, Pham VM, Mestres-Simon M, Andersen JF, Ribeiro JM: An insight into the sialome of the adult female mosquito Aedes albopictus. Insect Biochem Mol Biol 2007, 37:107-127.

18. Calvo E, Andersen J, Francischetti IM, deL CM, deBianchi AG, James AA, Ribeiro JM, Marinotti O: The transcriptome of adult female Anopheles darlingi salivary glands. Insect Mol Biol 2004, 13:73-88.

19. Francischetti IM, Valenzuela JG, Pham VM, Garfield MK, Ribeiro JM: Toward a catalog for the transcripts and proteins (sialome) from the salivary gland of the malaria vector Anopheles gambiae. J Exp Biol 2002, 205:2429-2451.

20. Ribeiro JM, Charlab R, Pham VM, Garfield M, Valenzuela JG: An insight into the salivary transcriptome and proteome of the adult female mosquito Culex pipiens quinquefasciatus. Insect Biochem Mol Biol 2004, 34:543-563.
21. Ribeiro JM, Arca B, Lombardo F, Calvo E, Phan VM, Chandra PK, Wikel SK: An annotated catalogue of salivary gland transcripts in the adult female mosquito, Aedes aegypti. BMC Genomics 2007, 8:6.

22. Neira OM, Ribeiro JM, Heyland A, Vanekeris L, Moroz T, Linser PJ: The salivary transcriptome of Anopheles gambiae (Diptera: Culicidae) larvae: A microarray-based analysis. Insect Biochem Mol Biol 2009, 39(5-6):382-94.

23. Choumet V, Carmi-Leroy A, Laurent C, Lenormand P, Rousselle JC, Namane A, Roth C, Brey PT: The salivary glands and saliva of Anopheles gambiae as an essential step in the Plasmodium life cycle: a global proteomic study. Proteomics 2007, 7:3384-3394.

24. Ghosh AK, Devenport M, Jethwaney D, Kalume DE, Pandey A, Anderson VE, Sultan AA, Kumar N, Jacobs-Lorena M: Malaria parasite invasion of the mosquito salivary gland requires interaction between the Plasmodium TRAP and the Anopheles saglin proteins. PLoS Pathog 2009, 5:e1000265.

25. Okulate MA, Kalume DE, Reddy R, Kristiansen T, Bhattacharyya M, Chaerkady R, Pandey A, Kumar N: Identification and molecular characterization of a novel protein Saglin as a target of monoclonal antibodies affecting salivary gland infectivity of Plasmodium sporozoites. Insect Mol Biol 2007, 16:711-722.

26. Nickel W: The mystery of nonclassical protein secretion. A current view on cargo proteins and potential export routes. Eur J Biochem 2003, 270:2109-2119.

27. Koutsos AC, Blass C, Meister S, Schmidt S, Maccallum RM, Soares MB, Collins FH, Benes V, Zdobnov E, Kafatos FC, et al: Life cycle transcriptome of the malaria mosquito Anopheles gambiae and comparison with the fruitfly Drosophila melanogaster. Proc Natl Acad Sci USA 2007, 104:11304-11309.

28. Neira OM, Vanekeris L, Corena-McLeod MD, Linser PJ: A microarray-based analysis of transcriptional compartmentalization in the alimentary canal of Anopheles gambiae (Diptera: Culicidae) larvae. Insect Mol Biol 2008, 17:61-72.

29. Warr E, Aguilar R, Dong Y, Mahairaki V, Dimopoulos G: Spatial and sexspecific dissection of the Anopheles gambiae midgut transcriptome. BMC Genomics 2007, 8:37.

30. Das S, Dimopoulos G: Molecular analysis of photic inhibition of bloodfeeding in Anopheles gambiae. BMC Physiol 2008, 8:23.

31. So WV, Sarov-Blat L, Kotarski CK, McDonald MJ, Allada R, Rosbash M: Takeout, a novel Drosophila gene under circadian clock transcriptional regulation. Mol Cell Biol 2000, 20:6935-6944.

32. Hardin PE: The circadian timekeeping system of Drosophila. Curr Biol 2005, 15:R714-R722.

33. Xu PX, Zwiebel LJ, Smith DP: Identification of a distinct family of genes encoding atypical odorant-binding proteins in the malaria vector mosquito, Anopheles gambiae. Insect Mol Biol 2003, 12:549-560.

34. Mans BJ, Calvo E, Ribeiro JM, Andersen JF: The crystal structure of D7r4, a salivary biogenic amine-binding protein from the malaria mosquito Anopheles gambiae. J Biol Chem 2007, 282:36626-36633.

35. Calvo E, Mans BJ, Andersen JF, Ribeiro JM: Function and evolution of a mosquito salivary protein family. J Biol Chem 2006, 281:1935-1942.

36. James AA, Blackmer K, Marinotti O, Ghosn CR, Racioppi JV: Isolation and characterization of the gene expressing the major salivary gland protein of the female mosquito, Aedes aegypti. Mol Biochem Parasitol 1991, 44:245-253.

37. Valenzuela JG, Charlab R, Gonzalez EC, de Miranda-Santos IK, Marinotti O, Francischetti IM, Ribeiro JM: The D7 family of salivary proteins in blood sucking diptera. Insect Mol Biol 2002, 11:149-155.

38. Arca B, Lombardo F, Lanfrancotti A, Spanos L, Veneri M, Louis C, Coluzzi M: A cluster of four D7-related genes is expressed in the salivary glands of the African malaria vector Anopheles gambiae. Insect Mol Biol 2002, 11:47-55.

39. Isawa $H$, Yuda M, Orito $Y$, Chinzei $Y$ : A mosquito salivary protein inhibits activation of the plasma contact system by binding to factor XII and high molecular weight kininogen. J Biol Chem 2002, 277:27651-27658.

40. Calvo E, Mans BJ, Ribeiro JM, Andersen JF: Multifunctionality and mechanism of ligand binding in a mosquito antiinflammatory protein. Proc Natl Acad Sci USA 2009, 106:3728-3733.

41. Dimopoulos G, Seeley D, Wolf A, Kafatos FC: Malaria infection of the mosquito Anopheles gambiae activates immune-responsive genes during critical transition stages of the parasite life cycle. EMBO J 1998, 17:6115-6123. 
42. Rosinski-Chupin I, Briolay J, Brouilly P, Perrot S, Gomez SM, Chertemps T, Roth CW, Keime C, Gandrillon O, Couble P, et al: SAGE analysis of mosquito salivary gland transcriptomes during Plasmodium invasion. Cell Microbiol 2007, 9:708-724

43. Van Steijn GJ, Amerongen AV, Veerman EC, Kasanmoentalib S, Overdijk B: Chitinase in whole and glandular human salivas and in whole saliva of patients with periodontal inflammation. Eur J Oral Sci 1999, 107:328-337.

44. Rossignol PA, Lueders AM: Bacteriolytic factor in the salivary glands of Aedes aegypti. Comp Biochem Physiol B 1986, 83:819-822.

45. Christophides GK, Zdobnov E, Barillas-Mury C, Birney E, Blandin S, Blass C, Brey PT, Collins FH, Danielli A, Dimopoulos G, et al: Immunity-related genes and gene families in Anopheles gambiae. Science 2002, 298:159-165.

46. Dimopoulos G, Christophides GK, Meister S, Schultz J, White KP, BarillasMury C, Kafatos FC: Genome expression analysis of Anopheles gambiae: responses to injury, bacterial challenge, and malaria infection. Proc Nat Acad Sci USA 2002, 99:8814-8819.

47. Osta MA, Christophides GK, Vlachou D, Kafatos FC: Innate immunity in the malaria vector Anopheles gambiae: comparative and functional genomics. J Exp Biol 2004, 207:2551-2563.

48. Vlachou D, Schlegelmilch T, Christophides GK, Kafatos FC: Functional genomic analysis of midgut epithelial responses in Anopheles during Plasmodium invasion. Curr Biol 2005, 15:1185-1195.

49. Waterhouse RM, Kriventseva EV, Meister S, Xi Z, Alvarez KS, Bartholomay LC, Barillas-Mury C, Bian G, Blandin S, Christensen BM, et al: Evolutionary dynamics of immune-related genes and pathways in disease-vector mosquitoes. Science 2007, 316:1738-1743.

50. David JP, Strode C, Vontas J, Nikou D, Vaughan A, Pignatelli PM, Louis C, Hemingway J, Ranson H: The Anopheles gambiae detoxification chip: a highly specific microarray to study metabolic-based insecticide resistance in malaria vectors. Proc Natl Acad Sci USA 2005, 102:4080-4084

51. Lund AA, Rhoads DM, Lund AL, Cerny RL, Elthon TE: In vivo modifications of the maize mitochondrial small heat stress protein, HSP22. J Biol Chem 2001, 276:29924-29929.

52. Champagne DE, Smartt $C T$, Ribeiro JM, James AA: The salivary glandspecific apyrase of the mosquito Aedes aegypti is a member of the $5^{\prime}$ nucleotidase family. Proc Natl Acad Sci USA 1995, 92:694-698.

53. Ribeiro JM, Francischetti IM: Role of arthropod saliva in blood feeding: sialome and post-sialome perspectives. Annu Rev Entomol 2003, 48:73-88.

54. Robertus JD, Monzingo AF, Marcotte EM, Hart PJ: Structural analysis shows five glycohydrolase families diverged from a common ancestor. J Exp Zool 1998, 282:127-132.

55. Altschul SF, Madden TL, Schaffer AA, Zhang J, Zhang Z, Miller W, Lipman DJ: Gapped BLAST and PSI-BLAST: a new generation of protein database search programs. Nucleic Acids Res 1997, 25:3389-3402.

56. Calvo E, Dao A, Pham VM, Ribeiro JM: An insight into the sialome of Anopheles funestus reveals an emerging pattern in anopheline salivary protein families. Insect Biochem Mol Biol 2007, 37:164-175.

57. Marinotti $\mathrm{O}$, Nguyen $\mathrm{QK}$, Calvo E, James AA, Ribeiro JM: Microarray analysis of genes showing variable expression following a blood meal in Anopheles gambiae. Insect Mol Biol 2005, 14:365-373.

58. Thangamani S, Wikel SK: Differential expression of Aedes aegypti salivary transcriptome upon blood feeding. Parasit Vectors 2009, 2:34.

59. Kerlin RL, Hughes S: Enzymes in saliva from four parasitic arthropods. Med Vet Entomol 1992, 6:121-126.

60. Qiu XB, Shao YM, Miao S, Wang L: The diversity of the DnaJ/Hsp40 family, the crucial partners for Hsp70 chaperones. Cell Mol Life Sci 2006, 63:2560-2570.

61. Ribeiro JM, Valenzuela JG: Purification and cloning of the salivary peroxidase/catechol oxidase of the mosquito Anopheles albimanus. J Exp Biol 1999, 202:809-816.

62. Francischetti IM, Valenzuela JG, Ribeiro JM: Anophelin: kinetics and mechanism of thrombin inhibition. Biochemistry 1999, 38:16678-16685.

63. Calvo E, Tokumasu F, Marinotti O, Villeval JL, Ribeiro JM, Francischetti IM: Aegyptin, a novel mosquito salivary gland protein, specifically binds to collagen and prevents its interaction with platelet glycoprotein VI, integrin alpha2beta1, and von Willebrand factor. J Biol Chem 2007, 282:26928-26938.

64. Yoshida S, Sudo T, Niimi M, Tao L, Sun B, Kambayashi J, Watanabe H, Luo E, Matsuoka $\mathrm{H}$ : Inhibition of collagen-induced platelet aggregation by anopheline antiplatelet protein, a saliva protein from a malaria vector mosquito. Blood 2008, 111:2007-2014.

65. Lin MZ, Greenberg ME: Orchestral maneuvers in the axon: trio and the control of axon guidance. Cell 2000, 101:239-242.

66. Terenius $O$, Marinotti $O$, Sieglaff $D$, James AA: Molecular genetic manipulation of vector mosquitoes. Cell Host Microbe 2008, 4:417-423.

67. Benedict MQ: Care and maintenance of Anopheline mosquitoes. In The molecular biology of disease vectors: A methods manual. Edited by: Crampton JM. London: Champman 1997:3-12.

68. Dong Y, Aguilar R, Xi Z, Warr E, Mongin E, Dimopoulos G: Anopheles gambiae immune responses to human and rodent Plasmodium parasite species. PLoS Pathog 2006, 2:e52.

69. Pfaffl MW: A new mathematical model for relative quantification in realtime RT-PCR. Nucleic Acids Res 2001, 29:e45.

70. Aguilar R, Das S, Dong Y, Dimopoulos G: Continuous exposure to Plasmodium results in decreased susceptibility and transcriptomic divergence of the Anopheles gambiae immune system. BMC Genomics 2007, 8:451.

71. Blandin S, Moita LF, Kocher T, Wilm M, Kafatos FC, Levashina EA: Reverse genetics in the mosquito Anopheles gambiae: targeted disruption of the Defensin gene. EMBO Rep 2002, 3:852-856.

72. Warr E, Das S, Dong Y, Dimopoulos G: The Gram-negative bacteriabinding protein gene family: its role in the innate immune system of Anopheles gambiae and in anti-Plasmodium defence. Insect Mol Biol 2008, 17:39-51.

73. Ribeiro JM: Blood-feeding in mosquitoes: probing time and salivary gland anti-haemostatic activities in representatives of three genera (Aedes, Anopheles, Culex). Med Vet Entomol 2000, 14:142-148.

doi:10.1186/1471-2164-11-566

Cite this article as: Das et al:: Transcriptomic and functional analysis of the Anopheles gambiae salivary gland in relation to blood feeding. BMC Genomics 2010 11:566.

\section{Submit your next manuscript to BioMed Central and take full advantage of:}

- Convenient online submission

- Thorough peer review

- No space constraints or color figure charges

- Immediate publication on acceptance

- Inclusion in PubMed, CAS, Scopus and Google Scholar

- Research which is freely available for redistribution

Submit your manuscript at www.biomedcentral.com/submit
C Biomed Central 